\title{
A QUADRATURA DO CÍRCULO: MÍNIMOS SOCIAIS, DIGNIDADE HUMANA E DIREITOS ADQUIRIDOS NA HIPERMODERNIDADE
}

\section{THE QUADRATURE OF THE CIRCLE: SOCIAL MINIMUMS, HUMAN DIGNITY AND RIGHTS ACQUIRED IN HYPERMODERNITY}

"A lei é poderosa; mais poderosa, porém, é a necessidade" (Goethe).

\begin{abstract}
Raimundo Márcio Ribeiro Lima
Professor Assistente I do Curso de Direito da UERN (2017). Doutorando em Direito Constitucional pela UFC. Doutorando em Direito Público pela Universidade de Coimbra. Mestre em Direito Constitucional pela UFRN (2012). Especialista em Direito Público, com habilitação em Direito Administrativo, pela UnB (2010). Especialista em Docência do Ensino Superior pela UnP (2010). Graduado em Direito pela UFC (2003). Procurador Federal - AGU (2004). Procurador-chefe da Procuradoria Federal na UFERSA (PF/UFERSA). Advogado OAB/RN. Tem experiência na área de Direito Público, com ênfase em Direito Administrativo, Constitucional e Previdenciário. Associado do Instituto Brasileiro de Advocacia Pública (IBAP). E-mail: marcio.ribeiro@ufersa.edu.br
\end{abstract}

Recebido em: 14/02/2017

Aprovado em: 09/05/2017

RESUMO: O artigo discute os limites da perspectiva normativa dos direitos sociais, especialmente a partir da compreensão normativa do princípio da dignidade humana, denunciando sua inutilidade, na maioria dos casos, para solucionar a problemática dos direitos sociais, pois ela exige o equacionamento de importantes variáveis extrajurídicas, sobretudo, políticas e econômicas. Discute-se também a questão do mínimo social como uma teoria objetivista e não minimalista da exigibilidade dos direitos, destacando a importância de uma atuação prioritária da ação pública. Por fim, critica a teoria imunizadora dos direitos, porquanto pode servir mais para defender privilégios odiosos que promover justiça social, sobretudo, quando a revisibilidade do atual regime previdenciário é impostergável.

Palavras-chave: Mínimo Social. Dignidade humana. Direitos adquiridos.

ABSTRACT: The article discusses the limits of the normative perspective of social rights, especially from the normative understanding of the principle of human dignity, denouncing their inutility, in most cases, to solve the problem of social rights, because it requires the equation of important extrajuridic variables, above all, political and economic. It also discusses the issue of the social minimum as an objectivist and non-minimalist theory of the enforceability of rights, highlighting the importance of a priority role of public action. Finally, it criticizes the immunizing theory of rights, since it may serve more to defend hateful privileges than to promote social justice, especially when the revisability of the current social security system can not be postponed.

Keywords: Social minimum. Human dignity. Acquired rights. 
RESUMEN: El artículo discute los límites de la perspectiva normativa de los derechos sociales, especialmente desde la comprensión del contenido normativo del principio de la dignidad humana, denunciando su inutilidad, en la mayoría de los casos, para resolver los problemas de los derechos sociales, ya que requiere ajustar importantes variables extralegales. También se discute el tema del mínimo social como una teoría objetivista y no minimalista de la aplicabilidad de los derechos, destacando la importancia de la actuación prioritaria de la acción pública. Por último, critica la teoría inmunizante de los derechos, porque puede servir más para defender privilegios odiosos que promover la justicia social, especialmente cuando la revisión del régimen de seguro social no puede ser pospuesto.

Palabras Clave: Mínimo social. Dignidad humana. Derechos adquiridos.

SUMÁRIO: Introdução. 1 Dignidade humana entre a técnica e a retórica. 2 Socialidade e mínimos sociais. 3 Direitos adquiridos na hipermodernidade. Conclusão. Referências Bibliográficas.

\section{INTRODUÇÃO}

É famosa a problemática da quadratura do círculo, que consistia em tentar formar, com régua e compasso, um quadrado com a mesma área de um círculo. Esse desafio, que animou matemáticos desde a Antiguidade, restou comprovadamente insolúvel, uma vez que Carl Louis Ferdinand Von Lindermann ${ }^{1}$, em 1882, demonstrou que seria impossível construir, com compasso e régua, uma área de um quadrado a partir da área de um círculo (O’CONNOR; ROBERTSON, 2001). De todo modo, o matemático tedesco não negava a possibilidade de formar a área de um quadrado a partir da área de um círculo, contudo, tal tarefa não seria possível com uma régua e um compasso. Aqui, reside a chave de compreensão para muitas questões sociais: não é razoável tentar solucionar os problemas, atuais ou pretéritos, apenas a partir das ferramentas de antanho, na insistente compreensão de que as soluções possam advir de um experimentalismo fechado dos modelos decisórios de outras épocas.

Mesmo sem os desmedidos esforços da matemática pura, cuja abstração assume ares de um verdadeiro devaneio nas concretas dissensões da socialidade, qualquer cidadão pode afirmar que a régua e o compasso dos esforços institucionais do Estado parecem desconhecer qualquer solução na geometria dos grandes problemas sociais. Evidentemente, um problema clássico da geometria grega é, em tese, mais simples de ser contornado, pois a comprovação da impossibilidade de sua resolução não deixa de ser uma resposta passível de aceitação (CRIPPA, 2010, p. 605). Por outro lado, na seara dos conflitos sociais, toda ingente atuação que não demonstre uma solução, minimamente aceitável, revela, em per si, uma derrota das forças sociais envolvidas no processo.

Adentrando no universo da reflexão jurídica, quiçá, a tormentosa problemática dos direitos positivos, isto é, no sentido de que todo direito comporta uma dimensão positiva, portanto, uma atuação do Poder Público, inclusive os direitos de liberdade (KLATT, 2015, p. 355), apenas reflita as limitações do instrumental utilizado pela tecnologia jurídica, é dizer, mediante os atuais modelos/institutos da Ciência Jurídica não é possível resolver, a contento, os sérios conflitos políticos-jurídicos da sociedade hipermoderna (LIPOVETSKY, 2004, p. 51 e segs.). Aliás, a insistência nos vetustos parâmetros jurídicos, como que seguindo a convicção de uma revelação teológica, apenas consolida o malogro da longa jornada da exigibilidade dos direitos positivos. Vive-se uma intensa complexidade nas relações sociais que é, em grande medida, para o bem e para o mal, incompatível com as auspiciosas projeções de outras gerações, mormente na área jurídica. Trata-se, aliás, de uma advertência já antiga, que, independentemente

\footnotetext{
${ }^{1}$ Matemático alemão nascido em 12 de abril de 1852, na cidade de Hanover, e falecido, em 06 de março de 1939, na cidade de Munique.
}

Revista de Direito Brasileira | São Paulo, SP | v. 19 | n. 8 | p. 33 - 50 |Jan./Abr. 2018 
do recurso ao sono da princesa da fábula (SOARES, 2008, p. 23), açoita todos os dias até mesmo os mais desavisados atores do direito público.

Desse modo, toda discussão sobre dignidade humana, mínimos sociais e direitos adquiridos, como clara tríade discursiva, deve assumir os necessários prognósticos da contemporaneidade, com seus limites e, claro, com suas desejosas possibilidades no mundo hipermoderno.

\section{DIGNIDADE HUMANA ENTRE A TÉCNICA E A RETÓRICA}

Não há como negar a importância do alavancar teórico-normativo da dignidade humana após a Segunda Guerra mundial. É dizer, o castigo das horas de suplício fez ecoar para bem longe as razões para não mais suportá-las. E a dignidade humana, como valor e/ou técnica jurídica, foi o grande elemento discursivo dessas razões, cujas raízes religiosas, filosóficas ou sociológicas não tardaram em descortinar os grandes equívocos do passado, que, insistentemente, ainda rondam a contemporaneidade. Noutro giro, por mais que se questione a vacuidade do termo, é sempre possível destacar uma ideia de conteúdo mínimo (MCCRUDDEN, 2008, p. 679-680; BARROSO, 2013, p. 72-98; SARMENTO, 2016, p. 89-94) e, assim, capaz de firmar um pretenso núcleo compreensivo sobre a temática, que, por certo, não se encontra indene de críticas. Aliás, entre a crítica da técnica (refinamento doutrinário) e a técnica sem criticidade (coringa hermenêutico ${ }^{2}$ ), como que desvelando um instrumental novo sobre velhas questões, exsurge a questão prática da dignidade humana, qual seja, o seu indefectível apelo retórico-humanístico, por mais que o esmero da técnica possa vislumbrar o contrário, trata-se de princípio inarredavelmente vinculados aos amparos culturais de cada sociedade e, claro, à forma como essa cultura possa ser exercida, daí o porquê de a retórica humanística sempre espelhar os (des)valores sociais, ainda que pretensamente arrimada na melhor técnica jurídica.

Nesse contexto, a contraposição decisória entre as cortes constitucionais, a partir dos substratos hermenêuticos da dignidade humana (RAO, 2008, p. 204), e não se trata de uma realidade apenas brasileira, muito embora nela os excessos sejam realmente invulgares, faz recrudescer a relevância de conter os excessos na metódica interpretativa dos direitos fundamentais, notadamente os direitos sociais, senão a auspiciosa técnica jurídica perde espaço para a mera retórica humanística e, infelizmente, tendenciosamente arbitrária.

Como mera exemplificação, e sem qualquer alarde, veja-se o tratamento diferenciado dispensado ao véu islâmico na Alemanha e na França, o mesmo se diga quanto ao aborto nos Estados Unidos e na Alemanha. Excetuando-se os Estados Unidos, que possui uma cultura jurídica mais particular, os demais países são pretensamente alvissareiros na defesa dos direitos fundamentais; contudo, assumem posições, por vezes antagônicas, que não se harmonizam com a ideia universalizante de substratos normativos mínimos da dignidade humana. Por isso, tendo em vista a dignidade humana, sumariam-se algumas proposições sobre a árdua tarefa de concretização dos direitos positivos, nestes termos:

(a) o nó górdio dos direitos sociais não se assenta na dificuldade jurídica em identificar os parâmetros de proteção social, mas, sim, na multidisciplinar compreensão dos meios necessários à concretização desses direitos, daí que a afirmação de que tal posição ou situação jurídica não se revela compatível com a dignidade humana, para além da elementar acusação de uma negligente reflexão sobre o modo de resolução dos dilemas existenciais, não passa, na maioria dos casos, de uma esplendorosa retórica humanística, só que veiculada numa pretensa técnica discursivo-argumentativa;

\footnotetext{
${ }^{2}$ A feliz expressão é de Daniel Sarmento (2016, p. 308).

Revista de Direito Brasileira | São Paulo, SP | v. 19 | n. 8 | p. 33 - 50 |Jan./Abr. 2018
} 
(b) a hipertrofia da perspectiva individualista dos direitos do homem (LINHARES, 2008, p. 429) encontra largo amparo na interpretação egoística do princípio da dignidade humana, fazendo com que os permeios da solidariedade, onde dormitam os valores comunitários, assumam, indevidamente, um matiz autoritário ou simplesmente supressor das liberdades públicas. Aqui, é curioso afirmar que, a depender do país, tal advertência pode assumir outro matiz, isto é, que a excessiva defesa dos valores comunitários, a partir da dignidade humana, representaria um eventual sacrifício dos direitos individuais (RAO, 2008, p. 215);

(c) a dignidade humana como ferramenta de reforço dos valores comunitários e, com isso, assumindo um mecanismo de aperfeiçoamento das políticas públicas é, a toda evidência, algo bem diverso de sua perspectiva egoística dispensada nos sofríveis dilemas existenciais, que, na maioria dos casos, apenas reforça desmedidamente os direitos de liberdade em detrimento das prestações sociais abrangentes. Especialmente, como bem denuncia o Sistema Único de Saúde (SUS), sobre questões relacionadas aos onerosos tratamentos de doenças raras ou, simplesmente, de alto custo. Aliás, sobre a temática, é relevante destacar que o STF, por meio dos Recursos Extraordinários $\mathrm{n}^{\circ}$ 566.471/RN (BRASIL, 2007) e 657.718/MG (BRASIL, 2011), poderá equacionar razoavelmente a questão do fornecimento de remédios de alto custo pelo Poder Público, isto é, considerar as prementes necessidades dos cidadãos e as possibilidades financeiras do Estado. O julgamento conjunto desses recursos ainda se encontra suspenso, aliás, desde 28 de setembro de 2016, por conta do pedido de vista feito pelo Ministro Teori Zavascki;

(d) é necessário prestigiar a dignidade humana, na cadência dos direitos sociais, como parâmetro discursivo da responsabilidade solidária, mas sem o viés apelativo pretensamente assegurador de um mínimo social, pois é extremamente discutível sua delimitação procedimental/material no universo das convenções jurídicas; portanto, é preciso destacar uma dinâmica consolidadora dos direitos a partir das conquistas sistêmicas no universo das prestações sociais; e

(e) a pretensão de imprimir um mínimo social a partir da dignidade humana, inclusive pretensamente universal e baseada apenas numa perspectiva normativa, por mais que se cogite o contrário, tende a representar uma fórmula vazia se os condicionantes político-econômicos não se afigurarem favoráveis no cumprimento dessa árdua tarefa. A importância discursiva da dignidade humana, contudo, deve ser prestigiada como forma de denunciar a necessidade de avanços na proteção social e, claro, nortear os planos da ação pública no campo da socialidade.

Feitas essas considerações, cumpre destacar que a quadratura do círculo em matéria de direitos sociais consiste na intrincada tarefa de harmonizar um universo cada vez mais expressivo de demandas sociais justamente numa época de convergência político-econômica cada vez menos favorável quanto à expansão das forças materiais do Estado. Aliás, isso pode ser observado em diversas áreas, por exemplo, na previdência social, como harmonizar a dinâmica contributiva, conforme os prognósticos da solidariedade social, corporificada na sustentabilidade previdenciária (atuarial e financeira), sem sacrificar os interesses dos mais jovens e nem prejudicar os mais velhos.

Nesse ponto, é importante destacar que a idade mínima para aposentadoria por tempo de contribuição, numa perspectiva global, tende a aumentar não apenas em função da maior longevidade da população, mas por conta da acentuada redução da taxa de fecundidade da população mundial. No Brasil, a idade média de obtenção de aposentadora por tempo de contribuição é de 54 para os homens e 52 para as mulheres. Nesse sentido, soa estranho, aliás, um verdadeiro ponto fora da curva, que não exista no Regime Geral de Previdência Social (RGPS) uma idade mínima para aposentadoria por tempo de contribuição, especialmente quando a maior parte dos países da OECD exige uma idade mínima de 65 anos e, ainda assim, com igualdade de gêneros (TAFNER; BOTELHO; ERBISTI, 2015, p. 75). Recentemente, o Poder Executivo brasileiro, por meio da PEC 287/2016 (BRASIL, 2016), apresentada em 05 de dezembro de 2016, 
a despeito das críticas que a ela possam ser levantadas, tentará reduzir essa patente distorção, porquanto prescreve a idade mínima de 65 anos, inclusive com a relevante correção de suprimir o tratamento diferenciado entre homem e mulher, portanto, impondo a igualdade de gênero.

Aqui, sem que isso constitua um demérito à senda discursiva da dignidade humana, parece pouco provável que a solução dessa problemática esteja assentada na mera arrumação teórico-argumentativa da normatividade constitucional. Muito embora, para além da ideologia dos direitos adquiridos, não representa qualquer surpresa que a dignidade humana seja inadvertidamente arvorada contra eventual revisibilidade dos regimes previdenciários (SARLET, 2009, p. 94).

Portanto, a discussão filosófico-jurídica da dignidade humana comporta limites mais expressivos no universo dos direitos sociais, a despeito de sua inquestionável importância argumentativa, porquanto não revela soluções sobre a concretização dos direitos, especialmente nas hipóteses em que não se discute o dever de promover uma ação pública, mas, sim, os meios disponíveis de atuação defendidos pelo Direito na promoção dos objetivos sociais, exigindo-se, assim, o interdependente arranjo do privado e do público na construção desses nobres propósitos (LOUGHLIN, 2010, p. 462), o que traz à baila a ruidosa questão da promoção dos mínimos sociais.

Aqui, antes de tudo, é necessário gizar que a ideia de mínimo social, conforme o fluxo das necessidades humanas, não espelha uma compreensão institucionalmente desejável sobre a temática, porém se prende à dinâmica do viável em função dos condicionantes políticoeconômicos de qualquer realidade social. É dizer, “[...] numa sociedade livre, que constitua uma democracia pluralista, os direitos a prestações materiais do Estado correspondem a fins políticos de realização gradual ou que são direitos 'sob reserva do possível'" (ANDRADE, 2006, p. 1.064). Não há, portanto, qualquer pretensão de minimizar o nível de proteção social (WALDRON, 1993, p. 270), pelo contrário, apenas reconhecer o nível de proteção social capaz de ser suportado pela sociedade, sobretudo, por meio de uma contínua reflexão dos parâmetros materiais das prestações sociais.

Por outro lado, isso não quer dizer, por ser necessário afirmar, que o atual modelo econômico não mereça reparos ou que se imponha um processo de conformação sobre a [injusta] forma de acúmulo de riqueza na sociedade, mormente por conta dos deletérios efeitos que o desenvolvimento reverso ocasiona nos países econômica e financeiramente vulneráveis (THOMSON, 2007, p. 57). Aliás, os próprios custos que compreendem a estabilidade do Sistema Financeiro cobram, muitas vezes, um valor excessivamente alto dos Estados, comprometendo a pauta de investimentos da gestão pública. Trata-se de uma temática longe de uma solução adequada pelos órgãos internacionais ou nacionais de (des)controle da atividade financeira. Afinal, "[...] tornar o mercado mais eficiente não é em si mesmo uma virtude. A real questão é saber se a introdução deste ou daquele mecanismo de mercado vai aprimorar ou prejudicar a atividade" (SANDEL, 2013, p. 179).

Desse modo, defender a teoria do mínimo social em nada se assemelha com uma indiferente precarização dos níveis de proteção social, porquanto isso representaria um verdadeiro consentimento com a insuficiência de outros programas de afirmação socioeconômica dos cidadãos; logo, a questão adentra outro horizonte reflexivo, baseia-se na providencial noção de que o eventual sacrifício das possibilidades materiais do Estado, mormente nos impreteríveis investimentos nas matrizes básicas da socialidade, tais como, infraestrutura sanitária e de transportes, saúde, educação e trabalho, não justificaria uma dinâmica protetiva dos direitos sociais que, além de excessivamente onerosa, não fosse capaz de firmar uma autonomia políticoeconômica dos cidadãos.

Noutro giro, a perspectiva reversa dos investimentos sociais não pode ser desprezada, especialmente numa ambiência de escassez de recursos, já que é sempre possível identificar nichos prioritários da ação pública. De igual modo, reputa-se desastrosa a recente política 
governamental, de natureza seletiva e exclusivista, de desoneração tributária na folha de pagamentos, cujos impactos no caixa do RGPS não podem ser desconsiderados nos arranjos macroeconômicos da política econômica brasileira; sobretudo, quando não ocorreram conquistas relevantes no aumento do emprego formal e, claro, na expansão da atividade econômica. Aliás, a ausência de parâmetros mínimos da atuação pública pode ser compreendida em 02 (dois) aspectos:

(a) na superposição dos direitos em face das possibilidades materiais do Estado e, por conseguinte, da sociedade civil, fazendo com que a autonomia do direito possa alcançar o cume da irresponsabilidade normativa. Aqui, evidentemente, não se trata da autonomia do Direito para, refletindo sobre o universo das práticas jurídicas, encontrar formas e meios de sua continuidade na árdua tarefa de superação dos dilemas da sociedade; e

(b) na privação dos direitos sociais, devidamente identificada na insuficiência dos parâmetros de proteção social, denunciando que os parâmetros normativos, se existentes, não são capazes de criar mecanismos reais de ação pública. A vida em extremos é sempre mais difícil, tratando-se dela a partir da gestão pública, então, é simplesmente inviável.

É preciso encontrar o meio termo da responsabilidade solidária, devidamente verificada na revisão contínua da ação pública por meio da consagração dos valores comunitários, não caindo nos extremos da perspectiva normativista dos direitos positivos a partir da dignidade humana ou no reducionismo das prescrições meramente econômicas das projeções sociais, geralmente fadadas ao ocaso da proteção social.

\section{SOCIALIDADE E MÍNIMOS SOCIAIS}

O mundo parece empreender uma (i)lógica fórmula evolutiva ao longo dos séculos: quanto mais avançam os progressos tecnológicos maiores são os flagelos da humanidade e mais intensa é a exclusão social; enfim, maior é a variação dos níveis de liberdade/capacidade dos cidadãos nos discutíveis planos da existência humana. De que adianta toda a evolução tecnológica se a fome ainda corrói boa parte do mundo e açoita diuturnamente as reflexões entusiásticas do progresso científico, que assume indesejáveis ares de nova colonialidade.

Ora, se há uma miríade de situações fáticas, nas quais demandam uma atuação do Poder Público, é compreensível que a noção de mínimo social contemple uma plurissignificação de prestações sociais no universo das políticas públicas. Nesse sentido, a ideia de mínimos sociais possui um forte apelo discursivo e, mais que isso, uma inquebrantável justificação no universo das reflexões político-jurídicas, pois não é admissível, numa sociedade que gera tantas riquezas, e o caso brasileiro é induvidosamente emblemático, uma aceitação passiva de situações de prementes necessidades dos cidadãos. Por certo, não é todo dilema existencial que justifique uma prestação social, seja porque alguns são simplesmente insolúveis, seja porque outros são injustificáveis em face dos encargos da socialidade, isto é, não se trata de uma prestação que deva ser suportada pela sociedade.

Contudo, o dilema reside na identificação de parâmetros materiais relativos aos mínimos sociais, porquanto resulta fora da realidade a compreensão de que eles sejam precipuamente partejados a partir dos princípios jurídicos de cunho social, nomeadamente o da dignidade humana. Além disso, parece pouco aconselhável que as matrizes decisórias estrangeiras sejam capazes de apresentar soluções adequadas, e pretensamente objetivas, a partir de uma analítica exposição da realidade fático-jurídica de determinada sociedade. Assim, a dinâmica da socialidade no Brasil é bem diversa da que é cotejada em Portugal, que, por sua vez, difere da verificada na Hungria. 
Evidentemente, isso não quer negar a importância do diálogo judicial ou institucional, mas, sim, focar na forma como ele pode ser adequadamente realizado e, sobretudo, destacar a importância dos condicionantes políticos, econômicos e sociais de cada Estado. Aliás, enxergar os limites dos processos decisórios estrangeiros, porque pensados para uma realidade diversa, possui o grande mérito de extrair os pontos que possam ser gravosos noutras paragens.

A questão dos mínimos sociais possui uma relação direta com o modelo de proteção social democraticamente concebido em determinada sociedade, sem olvidar, evidentemente, as imperiosas contingências socioeconômicas e históricas (WALDRON, 1993, p. 253), e, por conseguinte, não há uma dinâmica linear de atuação do Poder Público, muito embora existam preocupações comuns, notadamente na área da saúde, previdência social e assistência social.

Por isso, a noção de mínimo social é tão plurissignificante, já que não há como idealizar modelos ou mecanismos usualmente aplicáveis em qualquer sociedade, mesmo que se vislumbre uma ideia comum de renda mínima, porquanto se trata de matéria invariavelmente vinculada aos contextos nacionais (THOMSON, 2007, p. 60). É dizer, não se trata apenas da ingloriosa tarefa de identificar a compreensão normativa do mínimo social, sempre cercada de infindáveis controvérsias; mas, sobretudo, de definir os contornos materiais da própria noção normativa do mínimo social diante das possibilidades econômicas, políticas e culturais de cada sociedade.

Dito outro modo, saindo da perspectiva abstrata das questões jurídicas, adentrando no árido terreno dos dilemas concretos, o compromisso com os direitos positivos revela-se canhestro, ou mesmo inócuo, quando apartado dos limites compreensivo-operativos de outros ramos do conhecimento, tais como, gestão pública, política, economia etc. Aliás, a própria policentricidade $^{3}$ na complexa tarefa de alocação de recursos, mormente em âmbito nacional, na promoção das políticas públicas bem denuncia isso, especialmente numa ambiência de escassez.

Como a questão dos mínimos sociais não é preponderantemente jurídica, ainda que isso seja uma observação óbvia, mas pouco considerada nos quadrantes da atividade judicial, resulta extremamente pretensiosa a tarefa de definir os parâmetros mínimos de prestação social baseado apenas no núcleo principiológico da socialidade, notadamente no princípio da dignidade humana. Por isso, a dinâmica dos mínimos sociais exige alguma objetividade no tratamento da matéria, o problema, contudo, reside no fato de que, no campo da socialidade, toda objetividade possui uma carga de arbitrariedade, especialmente no universo das prestações sociais, gerando dissensos relevantes na consecução das políticas públicas. Em outras palavras, toda toada de racionalidade é compreendida como meramente utilitarista e, assim, supressora do adequado tratamento aos dilemas existenciais.

Nesse ponto, vale destacar que, não raras vezes, são ventiladas perspectivas teóricas (NOVAIS, 2010, p. 309) que tentam superar determinadas construções doutrinárias relacionadas à efetivação dos direitos sociais, inclusive com demoradas e contundentes críticas; todavia, utilizando-se da mesma estrutura de armas, a saber, centrada na ideia de mínimo social e dignidade humana. Com efeito, as construções teóricas criticadas estão relacionadas à ideia de mínimo existencial, mínimo vital, direito a um mínimo para uma existência condigna etc. Em verdade, essas teorias não são minimalistas, mas desejosamente objetivistas, justamente por tentar romper o largo processo discursivo sobre direitos sociais, mormente numa contextura de escassez de recursos, a partir dos imprevisíveis prognósticos exegéticos judiciais decantados por meio do princípio da dignidade humana, que vem comprometendo a principal tarefa do direito, que é a sua unidade sistemática (DINIZ, 2016, p. 93).

Ora, em que sentido os juristas negam ou negariam a importância da dignidade humana para sustentação dos direitos sociais, a despeito de toda problemática que tal opção inevitavelmente encerra na fundamentação dos direitos (CORTINA, 2007, p. 244)? Além disso, como admitir que a dignidade humana tivesse um conceito pronto e, assim, capaz de firmar

${ }^{3}$ Com princípio da autocontenção judicial, vide Jeff King (2012, p. 189-210).

Revista de Direito Brasileira | São Paulo, SP | v. 19 | n. 8 | p. 33 - 50 |Jan./Abr. 2018 
compreensões passíveis de consenso na arena pública. De todo modo, como conceber a dinâmica fundamentadora dos direitos fundamentais sem a dignidade humana? Só que a problemática reside propriamente em outro universo discursivo, a saber, que parâmetro material da dignidade humana pode ser exigido da sociedade: a que decorre dos vislumbres exegéticos dos atores processuais ou das analíticas considerações da estrutura orgânico-funcional responsável justamente pelas prestações sociais? Aqui, adverte-se: "[n]a verdade, para concretização do direito, o legislador tem de fazer opções técnicas e sobretudo políticas, que devem ser avaliadas em função dos princípios de realidade ou de substancialidade" (ANDRADE, 2004, p. 27, itálico no original).

Essa assertiva pode soar alheia aos imperativos da normatividade constitucional conformadora da socialidade no Estado Democrático de Direito, porém, ao revés, é uma pura expressão da providencial compreensão das competências definidas no texto constitucional, que não comporta matrizes decisórias que vão além dos imperiosos limites que salvaguardam o equilíbrio entre os Poderes da República, pelo menos numa perspectiva funcional. Isso, evidentemente, não quer dizer que as decisões tomadas pelo Poder Legislativo sejam sempre adequadas ou exaurientes na controvertida tarefa de concretização dos direitos sociais, como que invariavelmente formulasse o melhor conjunto de possibilidades no universo da atuação estatal, mas, sim, que a reflexão sobre tais decisões na ciranda processual, no que se impõe a questão de agregar técnicas ou expertise no processo de aperfeiçoamento dos mecanismos de proteção social (VERMEULE, 2006, p. 183-184), não deva promover uma superposição do Poder Judiciário no deslinde das grandes questões sociais, exigindo-se, aqui, a providencial adoção dos diálogos institucionais, como via procedimental de toda dinâmica persuasiva (CORTINA, 1988, p. 166), que possui o grande mérito de alavancar a concorrência entre instituições no processo de definição do significado constitucional das políticas públicas (TUSHNET, 2008, p. 228), até porque uma patente lição do moderno Estado de bem-estar, que remonta à segunda metade do século passado, é que dilemas estruturais de uma sociedade, como pobreza ou renda mínima, não podem ser contornados por uma instituição isoladamente (WALDRON, 1993, p. 269). Além disso, como a dinâmica da renda mínima é tão necessária quanto incompleta, e por isso passível de prestação social numa perspectiva abrangente, então, somente é possível contemplar o atendimento de outras demandas, também numa perspectiva ampla, a partir do envolvimento de todas as instituições no largo processo de aferição das possibilidades da ação pública, tendo em vista o desenvolvimento social alcançado com os programas anteriores, exitosos ou não.

Por isso, julgados de grande expressão social, como o Acórdão no 509/2002 do Tribunal Constitucional português (PORTUGAL, 2002) ${ }^{4-5}$, o caso Grootboom (ÁFRICA DO SUL, 2000) da Corte Constitucional sul-africana ou, ainda, a Ação Direta de Inconstitucionalidade $\mathrm{n}^{\circ}$ 1.232/DF do Supremo Tribunal Federal (BRASIL, 1998), num reflexivo exercício de autolimitação, recorrem ao apelo pretensamente técnico-racional das opções políticas, porque, até que advenha uma analítica comprovação em sentido contrário, elas expressam os limites políticoeconômicos da sociedade e, mais que isso, compreende o modelo seguido pela gestão pública, conforme a regular reflexão e cadência no tempo, para empreender os objetivos fundamentais determinados pelo texto constitucional.

Esse entendimento, inclusive, foi expressamente seguido no caso Grootboom, nestes termos: "In determining whether a set of measures is reasonable, it will be necessary to consider housing problems in their social, economic and historical context and to consider the capacity of

\footnotetext{
${ }^{4}$ Numa perspectiva anterior, precisamente no Acórdão no 349/1991, transcreve-se: “[...] ainda que não possa ver-se garantido no artigo $63 .^{\circ}$ da Lei Fundamental um direito a um mínimo de sobrevivência, é seguro que este direito háde extrair-se do princípio da dignidade da pessoa humana, condensado no artigo $10^{\circ}$ da Constituição [...]" (PORTUGAL, 1991).

${ }_{5}^{5}$ Para uma síntese da discussão jurisprudencial da socialidade em Portugal, vide Ana Raquel Gonçalves Moniz (2015, p. 83-100).
}

Revista de Direito Brasileira | São Paulo, SP | v. 19 | n. 8 | p. 33 - 50 |Jan./Abr. 2018 
institutions responsible for implementing the programme" (ÁFRICA DO SUL, 2000, item 43, p. $33)^{6}$.

Porém, no que concerne ao julgado do tribunal brasileiro, é necessário afirmar que a ADI $n^{\circ}$ 1.232/DF, desde o ano de 2013, foi superada pela jurisprudência do STF, haja vista o Acórdão prolatado na Reclamação $n^{\circ}$ 4.374/PE (BRASIL, 2013), que considerou inconstitucional o critério da renda per capita, previsto no artigo $20, \S 3^{\circ}$, da Lei $n^{\circ} 8.742 / 1993$, pois se encontra defasado para declarar a situação de miserabilidade das famílias, tendo em vista que outros programas sociais possuem parâmetros mais elásticos.

Aqui, reside um dos mais notórios dilemas em matéria de mínimo social, a saber, o desprezo dos benefícios comuns, considerados como de menores custos, mas de maior abrangência, fazendo com que, como no caso da Assistência Social brasileira, ocorra uma onerosidade excessiva das prestações sociais, sem que os resultados esperados pela política pública ocorram, a contento, em determinado segmento da sociedade, precisamente o desejado pela ação pública, sem falar que a política de mínimo social pode revelar-se, paradoxalmente, um máximo social, no sentido de que onera em demasia a política pública, inviabilizando outras formas de atuação prioritária da gestão pública (WIDERQUIST, 2010, p. 478).

Nesse ponto, por exemplo, basta considerar o exponencial aumento dos gastos com benefício assistencial de prestação continuada, com o sacrifício do necessário aperfeiçoamento do Programa Bolsa Família (PBF), por meio da seletividade, do controle e acréscimo de valor, tal como, infelizmente, admitiu o STF, tendo em vista a relativização do critério da renda per capita. Aliás, tal fato representa forçosamente um verdadeiro erro da gestão pública, mormente numa ambiência de escassez, pois o PBF revelou-se bem mais eficiente que o benefício assistencial idoso/deficiência no combate da pobreza, sobretudo, das crianças (GIAMBIAGI; TAFNER, 2010, p. 143-144; RAVALLION, 2016, p. 471), sem falar que, dentre seus efeitos, encontra-se uma melhoria significativa na área de educação e saúde, consagrando, assim, uma política pública que tenta consagrar um verdadeiro resgate da cidadania (FARIA; SILVA, 2016, p. 161).

Além disso, na Reclamação $n^{\circ}$ 4.374/PE (BRASIL, 2013) também foi declarada a inconstitucionalidade do artigo 34, § único, da Lei $\mathrm{n}^{\circ}$ 10.741/2003 (BRASIL, 2003), porquanto cria parâmetros diversos, para fins de eventual aferição de renda per capita, entre benefício assistencial ou previdenciário de valor mínimo.

Tendo em vista essas vicissitudes na compreensão das prestações sociais, o que isso demonstra? Que a ideia de mínimo social é contingencial, porquanto as convergências políticoeconômicas podem levar à superação das antigas barreiras fiscais no regular prognóstico das prestações sociais.

Essa afirmação não desprezaria a importância da eficácia jurídica dos textos constitucionais? De modo algum, numa ambiência de forte desigualdade social (RAVALLION, 2016, p. 470), com inegáveis, contínuos e restritos fluxos de acúmulo de riqueza, já que os mais pobres ainda não se beneficiam adequadamente do crescimento agregado (RAVALLION, 2016, p. 470), apesar de inegáveis avanços no largo, e ainda insuficiente, processo de capacitação da população brasileira, a justiça distributiva não encontra apelo apenas nos fulgurantes alaridos ideológicos esquerdistas, não mesmo, arrima-se, e principalmente, no substrato das categóricas imposições normativas; contudo, e isso precisa ficar bem claro, os limites operativos do Direito, mormente na formação dos instrumentais jurídicos adequados na promoção da justiça social, não podem ser desconsiderados e, justamente por isso, numa ambiência de escassez, poucos não são os expedientes político-econômicos encetados para evidenciá-los, seja por meio dos entraves materiais da economia, seja por meio dos impasses políticos.

\footnotetext{
6 "Para determinar se um conjunto de medidas é razoável, será necessário considerar os problemas de habitação em seu contexto social, econômico e histórico e considerar a capacidade das instituições responsáveis pela implementação do programa" (tradução nossa).
} 
Aqui, é preciso identificar o discurso da escassez (a) como estado e (b) como ideologia. Como induvidosa situação fiscal, a escassez representa o norte da atuação pública decantada no estreitamento das prioridades das prestações sociais; por outro lado, no condenável aspecto ideológico, a escassez não passa de uma ferramenta política, com claro substrato econômico, que tende a imprimir reformas para consolidar interesses inconfessáveis da ciranda política.

De todo modo, não parece ser a atuação judicial o protagonista do elenco das forças institucionais do Estado destinadas a desatar o nó górdio das reformas estruturais da sociedade. Numa palavra: nenhuma jurisdição constitucional, a ferro e fogo, obtém resultados desejáveis no campo da socialidade, exige-se uma concorrência de fatores que, conjuntamente com os precisos nortes jurídicos, faça brotar as soluções no campo da socialidade. Nesse sentido, os senhores de Karlsruhe pouco poderiam fazer no Zimbábue, ou mesmo no Brasil, a partir dos dilemas sociais desses países. Não se trata de um reducionismo sociológico, político ou econômico, mas, tão somente, considerar que a ciranda jurídica carece de outras instâncias decisórias no largo processo reflexivo, este inevitavelmente exigido, no desenlace dos grandes problemas da sociedade hipermoderna.

Ora, mencionar que o mínimo social é contingencial não quer dizer que ele necessite ser juridicamente volátil, mas, sim, que o mero substrato axiológico-normativo não sustenta qualquer patamar de socialidade, nem mesmo a ideia de mínimo social, quando não possui a seu favor substratos político-econômicos favoráveis. Tem-se, assim, o vazio da correção jurídica no amplíssimo universo dos desafios materiais da gestão pública. O que explica a controvérsia ou diversidade sobre a ideia de mínimo social em cada sociedade é justamente a disparidade de substratos político-econômicos reinante em cada país. Esse é o verdadeiro sentido que se extrai da afirmativa de que todo mínimo social é contingencial. Afirmar o contrário é defender o direito constitucional da fantasia, como se o castelo de cartas de uma construção jurídica coerente fosse capaz, por si só, de levantar o frondoso edifício da exigibilidade dos direitos sociais. A importância da atuação judicial, tendo em vista essa constatação, resulta na imperiosa necessidade de aperfeiçoar os procedimentos e as instituições, fazendo com que os mecanismos de atuação da ação pública, notadamente na área dos serviços públicos, sejam mais eficientes e responsáveis, isto é, submetam-se às ordinárias ou extraordinárias vias de controle social. Não é uma tarefa simples, mas é a que permite uma atuação judicial saia do cômodo universo das imposições normativas, porque centradas numa defensável construção teórica, mas alheia à ambiência dos dilemas materiais da gestão pública.

Desse modo, sem cair numa compreensão estéril da problemática e, portanto, não olvidando a importância de um nível mínimo de proteção social, defende-se a dinâmica consagradora do mínimo social por meio de conjunto de medidas político-econômicas, devidamente aperfeiçoadas no regular curso das políticas públicas, tendo em vista os seguintes pontos:

(a) como cada Estado possui seu sistema de proteção social, a noção de mínimo social é centrada na multiplicidade das políticas públicas, que, em conjunto, seja capaz de fornecer as condições para uma vida condigna;

(b) renda mínima, necessidades ou capacidades representam o universo reflexivo do mínimo social, de maneira que a dinâmica protetiva não pode tratar esses elementos isoladamente; e

(c) o mínimo social não pode desconsiderar os benefícios comuns, geralmente mais abrangentes, menos exigentes quanto aos parâmetros concessórios e isoladamente poucos onerosos, refletindo sempre sobre a utilidade deles em função dos objetivos perseguidos nos grupos ou segmentos prioritários, tais como, velhos, pessoas com deficiência ou crianças. 
Assim sendo, a questão da renda mínima exige a identificação de nichos sociais específicos, cuja premente necessidade deve ser resolvida com maior brevidade possível, como é o caso da fome ou analfabetismo, pois como é possível se preocupar com a cortina da janela, se a janela se encontra quebrada ou simplesmente ainda não há janela. Defender planos mínimos, mas abrangentes de atuação pública, não é negar a importância de prestações mais protetivas, mas, sim, estabelecer prioridades da ação pública, porquanto é certo que tudo pode ser alcançado concomitantemente.

Por outro lado, a questão da isenção tributária sobre bens essenciais (cesta básica) deve ser a mais ampla possível, porquanto isso reduz os custos da tributação indireta, sem falar nos prognósticos positivos da capacidade contributiva na compreensão responsabilidade solidária no campo da socialidade, e, por fim, a questão da atenção prioritária dos serviços públicos deve obedecer ao regime de escala, isto é, porquanto são mais abrangentes e, nesse sentido, menos onerosos que as prestações individuais, sem que isso represente a possibilidade de formas extraordinárias de prestação pública, contanto que não os limites da responsabilidade físcal.

\section{DIREITOS ADQUIRIDOS NA HIPERMODERNIDADE}

"O Brasil não tem problemas, só soluções adiadas" 7 . Nesse sentido, a teoria dos direitos adquiridos cumpre fielmente o condenável imobilismo da máxima cascudiana, pois o seu discurso, além de inebriante, possui uma ímpar capacidade de postergar as reformas para uma prosperidade que, todavia, teima em chegar.

Há, nesse discurso, como que um ar de autonomia compreensiva totalmente linear e de irretocável justiça social; contudo, ele é dependente de diversos fatores e, claro, a ideia de justiça, na maioria dos casos, revela-se apenas vestigial. A manutenção de privilégios odiosos, mormente para determinados segmentos da sociedade, seria um bom exemplo disso, como bem denuncia, aliás, de modo flagrante, a aposentadoria punitiva dos membros da Magistratura e membros do Ministério Público ${ }^{8}$, que, a despeito de possuir natureza disciplinar, representa um verdadeiro prêmio a esses servidores, que descumprem glamourosamente seus deveres funcionais, caso contrário, tendo em vista o forte corporativismo que reina nessas instituições, não seriam punidos.

Como defender ou admitir estoicamente o discurso dos direitos adquiridos direitos diante da irrefragável condicionalidade dos direitos na sociedade hipermoderna? Isto é, como fazer imperar a opacidade de um túmulo sobre questões incandescentes, que açoita a todos, mesmo no mais distante rincão do país, sobre a sustentabilidade das políticas públicas, especialmente numa ambiência de escassez, que sacrifica fortemente o poder de investimento do Estado? Por tudo, é preciso destacar que a segurança gerada pelos direitos adquiridos não pode ser sustentada à custa do sacrifício dos benefícios das gerações presentes e, sobretudo, as futuras. Aqui, é preciso destacar 04 (quatro) pontos:

(a) nas sociedades com enormes desigualdades sociais e, sobretudo, com forte exclusão social, os direitos adquiridos assumem o status de verdadeiro mecanismo assegurador de odiosos privilégios corporativos e, desse modo, se contrapõem aos ideais de justiça distributiva. Desse modo, defende-se a mitigação da intangibilidade dos direitos adquiridos quando eles reforçam, por sua natureza ou propósito, os mecanismos ou processos de exclusão social (SAMPAIO, 2009, p. 340);

\footnotetext{
${ }^{7}$ Célebre frase atribuída a Luís da Câmara Cascudo, historiador, antropólogo, jornalista e advogado potiguar. Foi professor da Faculdade de Direito de Natal, hoje, Faculdade de Direito da Universidade Federal do Rio Grande do Norte. Nasceu em Natal, em 30 de dezembro de 1898, e faleceu, na mesma cidade, em 30 de julho de 1986.

${ }^{8}$ Conforme dispõem o artigo 93, inciso VIII, c/c artigo 129, $\S 4^{\circ}$, todos da Constituição Federal (BRASIL, 1988).
}

Revista de Direito Brasileira | São Paulo, SP | v. 19 | n. 8 | p. 33 - 50 |Jan./Abr. 2018 
(b) o turbilhão de mudanças que encerra a sociedade hipermoderna ${ }^{9}$ é incompatível com a tese imunizadora dos direitos estampada no artigo $5^{\circ}$, inciso XXXVI, da Constituição Federal (BRASIL, 1988), porquanto o fundado propósito de promover a segurança jurídica na relação Estado-cidadão, até mesmo como exigência operacional do sistema jurídico, não legitima a manutenção de posições ou situações jurídicas que sacrifique a utilidade dos próprios mecanismos de proteção social, tal como ocorre, aliás, sendo um dado nada invulgar, na recorrente questão da insustentável higidez financeira e atuarial dos regimes previdenciários;

(c) o difícil prognóstico da dinâmica demográfica (GIAMBIAGI; TAFNER, 2010, p. 27), que denuncia um expansivo assombroso déficit no orçamento da seguridade social caso persista o atual modelo contributivo/concessivo de regime previdenciário, para além das meras reflexões previdenciárias, tendo em vista a reduzida capacidade de investimento do Poder Público, exige providenciais alterações nos parâmetros jurídicos dos benefícios de proteção social, senão o discurso dos direitos adquiridos poderá ser o grande responsável pelo efetivo estrangulamento das políticas públicas abrangentes da seguridade social; e

(d) a ideologia dos direitos adquiridos corporifica, em grande medida, uma dinâmica conformadora dos direitos que se revela incompatível com as matrizes teóricas da responsabilidade solidária, conforme os ditames da ética da responsabilidade (CORTINA, 1988, p. 176), especialmente numa ambiência de escassez e de intensos riscos sociais, inclusive em escala global (BECK, 2009, p. 191).

Dito de outro modo: não há direito adquirido contra a realidade, contudo, é possível assegurar uma realidade pomposa e astuciosamente adquirida pelo direito. Em verdade, trata-se de uma objetável possibilidade no universo das relações jurídicas. De igual modo, a mesma objeção pode ser empreendida, com as devidas adaptações, com relação às teses estabilizadoras das relações jurídicas, sobretudo, no que se refere à vedação do retrocesso social e, ainda com maiores ressalvas, à proteção da confiança legítima, porquanto não é toda medida séria, e mesmo restritiva de direitos, que possa ser considerada excessivamente onerosa ou arbitrária (QUEIROZ, 2014, p. 29), já que a dura arena das decisões políticas impopulares não representa uma faculdade da política virtuosa, mas, sim, uma imperiosa necessidade, que se espera passageira.

Notadamente, em quaisquer casos, a objeção exige uma necessária força argumentativa capaz de afastar os imperiosos substratos normativos da intangibilidade dos parâmetros da estabilização jurídica, justamente por resultar gravosa aos necessários prognósticos de proteção social. A revisibilidade das relações jurídicas não pode exsurgir de um fetiche político, não mesmo, mas, sim, de uma providencial necessidade de compatibilizar o regime dos benefícios com as possibilidades financeiras da ação pública. A defesa da teoria imunizadora dos direitos possui uma projeção marcadamente individualista das garantias jurídicas, que só pode ser galhardamente defendida em função de categorias decisórias que adentrem no condenável campo da arbitrariedade ou insensatez política. Uma política virtuosa nada se assemelha a isso, em verdade, a ausência duma política séria na gestão fiscal do Estado é que faz exsurgir a questão da austeridade com remédio amargo e desmedido, sem perquirir, contudo, a razão das providenciais medidas de austeridade, que nada se confunde com a imposição de sacrifícios seletivos, especialmente dos menos favorecidos economicamente.

Ora, é curiosa a senda argumentativa dos direitos a partir dos pressupostos discursivos da segurança jurídica, pois, negando as dificuldades político-institucionais do Estado para gerir as demandas de proteção social a partir do mercado, e não apenas através dele, considera paradoxalmente o substrato econômico, que possibilita materialmente as políticas públicas, como um fato perene e, nesse sentido, também compaginável com a estabilidade dos direitos. O melhor

\footnotetext{
${ }^{9} \mathrm{Ou}$, se desejarem, os difíceis prognósticos da modernidade líquida, nas quais denunciam a liquefação dos padrões de dependência e interação no meio social, com que escancarando os conflitos que recai na assunção individualizada da modernidade (BAUMAN, 2001, p. 14).
}

Revista de Direito Brasileira | São Paulo, SP | v. 19 | n. 8 | p. 33 - 50 |Jan./Abr. 2018 
dos mundos, sem dúvida, poderia levar a esse entendimento; contudo, numa perspectiva econômica, os fatores limitadores dessa tese são tão evidentes, para não dizer ululantes, quanto à própria necessidade de criar mecanismos para promover a proteção social dos cidadãos. Dito de outro modo, não há como exigir um lar firme num terreno, por natureza, movediço: a economia. Por isso, a desejosa socialidade apenas numa perspectiva normativa é, induvidosamente, trôpega no inóspito da exigibilidade dos direitos sociais.

Tratando-se da previdência social, uma questão encontra-se fora de dúvida: a população brasileira envelhece numa projeção assustadora e, mesmo assim, há quem defenda um regime previdenciário baseado num modelo de benefícios concebido na primeira metade do século passado. A dinâmica demográfica revela um inevitável fluxo na estrutura etária brasileira: há cada vez menos jovens e há cada vez mais velhos, bem mais velhos.

Aliás, recentes dados demográficos comprovam isso tranquilamente. Por exemplo, em 2004, os maiores de 60 (sessenta) anos alcançavam apenas 9,7\% da população, mas, em 2014, eles alcançaram 13,7\% e vão passar, numa projeção de pouco mais de 04 (quatro) décadas, para 18,6\% e 33,7\%, respectivamente, nos anos de 2030 e 2060 (BRASIL, 2015, p. 14). Além disso, como parece ser um dado inevitável, a população entre 00 (zero) e 14 (catorze) anos alcançava, em 2004, um número na ordem de 27,1\%, porém, observa-se que, após uma década, esse percentual caiu para 21,6\% e vai chegar, numa projeção para pouco mais de 04 (quatro) décadas, para 17,6\% e 13,0\%, respectivamente, nos anos de 2030 e 2060 (BRASIL, 2015, p. 14).

Veja-se, também, a difícil relação entre a previdência social e o Produto Interno Bruto (PIB), este, evidentemente, não espelha o parâmetro mais preciso para aferir questões sociais; contudo, tendo em vista a reconhecida dificuldade de indexação da teoria das capacidades, representa uma clara amostra de que algo precisa ser feito, revelando que as despesas previdenciárias saíram de $8 \%$ do PIB, no ano de 2002, para 9,3\% do PIB no ano de 2015 (BRASIL, 2016, p. 10). Além disso, os gastos sociais do Governo saíram de 12,6\% do PIB, no ano de 2002, para 15,7\% do PIB, no ano de 2015 (BRASIL, 2016, p. 09), o que demonstra uma forte evolução na área social; contudo, o que se pode questionar é o nível de responsabilidade fiscal compreendido nesses investimentos, pois, numa convergência econômica desfavorável, a higidez financeira do Estado resulta totalmente comprometida e isso, por certo, afeta aspectos macroeconômicos relevantes, notadamente na seara da empregabilidade privada ou pública. Soma-se, ainda, o espantoso resultado do déficit da previdência social no ano de 2016, que, infelizmente, alcançou a importância de R \$ 149,7 bilhões de reais. Aliás, quando devidamente atualizado pelo INPC, esse déficit chega a incrível marca de $\mathrm{R} \$ 151,9$ bilhões de reais, lembrando-se que esse déficit era de R \$ 73,1 bilhões de reais no ano de 2003 (BRASIL, 2017).

Portanto, não há dúvida de que a reforma da previdência resulta impostergável. Vale gizar que a questão não se limita apenas a discutir se existe ou não recursos para manter o atual regime concessivo/contributivo do RGPS, mas, sim, em definir qual o percentual adequado do orçamento público deve ser destinado à previdência social, sem que ocorra um prejuízo na expansão de outras áreas sociais, que são igualmente relevantes para o desenvolvimento socioeconômico do país.

E o que isso quer dizer? Acredita-se que a manutenção dos atuais níveis de proteção social, que sequer atinge adequadamente toda a população brasileira, será seriamente comprometida na hipótese de resistir qualquer tese imunizadora de direitos, isto é, se ainda persistir incólume uma tese dos direitos adquiridos como mandamento constitucional absoluto. Numa palavra: a revisibilidade dos regimes previdenciários será uma constante, não uma desejosa atuação da atividade política, cujo ônus eleitoral é indiscutível, mas uma providencial constante numa gestão pública que pretenda ser responsável num Estado Democrático de Direito. 


\section{CONCLUSÃO}

Diante das considerações ventiladas e, sobretudo, pelas proposições apresentadas, sumaria-se o seguinte:

(a) a compreensão da dignidade humana como reforço axiológico-normativo das prestações sociais pouco contribui, em boa parte dos casos, para a concretização dos direitos sociais, porquanto o maior dilema dessa problemática não se refere ao arbítrio judicial de determinado grau de proteção social, mas, sim, aos meios e modos para promover determinadas prestações sociais, isto é, o aspecto institucional ou procedimental dessas prestações (ANDRADE, 2006, p. 1.063);

(b) numa ambiência de escassez e de profunda desigualdade social, para além das inevitáveis críticas das relações econômicas, a questão do mínimo social, ainda que no estreito limite da renda mínima, não pode ser precipuamente definida a partir do princípio da dignidade humana, até porque os valores que adornam a ideia de dignidade são, por definição, elásticos e plúrimos, sem falar que o dilema não resulta na identificação de eventual ofensa ao princípio da dignidade humana, porquanto a necessidade da ação pública resulta patente na maioria dos casos, o problema é outro, a saber, providenciar os meios materiais da atuação do Poder Público; e

(c) a teoria imunizadora dos direitos, corporificada na linear compreensão dos direitos adquiridos, numa convergência econômica desfavorável e, sobretudo, em função dos inevitáveis impactos de uma demografia desfavorável, pode representar um fator de manutenção de odiosos privilégios, que, além de causar sérios problemas relacionados à justiça intergeracional, compromete a gestão fiscal do Estado e, com isso, pode estancar o regular curso evolutivo das políticas públicas, o que nada contribui para resguardar a ideia de mínimos sociais, até porque quem se encontra numa posição de defesa/exigência de direitos adquiridos, certamente, já superou eventual/potencial quadro de dependência de um mínimo social, isto é, não se encontra numa situação de intervenção prioritária da ação pública.

\section{REFERÊNCIAS BIBLIOGRÁFICAS}

ÁFRICA DO SUL. Corte Constitucional. The Government of the Republic of South Africa \& Others vs Grootboom \& Others. 2000. Disponível em:

<http://www.saflii.org/za/cases/ZACC/2000/19.pdf>. Acesso em 14 dez. 2016.

ANDRADE, José Carlos Vieira de. O “Direito ao Mínimo de Existência Condigna” como Direito Fundamental a Prestações Estaduais Positivas - Uma Decisão Singular do Tribunal

Constitucional. Jurisprudência Constitucional. Coimbra, nº 01, p. 04-29, jan./mar. 2004.

ANDRADE, José Carlos Vieira de. Os direitos fundamentais no século XXI. In: CARRASCO DURÁN, Manuel; PÉREZ ROYO, Francisco Javier; URÍAS MARTÍNEZ, Joaquín; TEROL BECERRA, Manuel José (Coord.). Derecho constitucional para el siglo XXI: actas del VIII Congreso Iberoamericano de Derecho Constitucional. Vol. 1. Madrid: Editorial Aranzadi, 2006, p. 1.051-1.080.

BARROSO, Luís Roberto. A dignidade da pessoa humana no direito constitucional contemporâneo: a construção de um conceito jurídico à luz da jurisprudência mundial. Tradução Humberto Laport de Mello. 2a reimpressão. Belo Horizonte: Fórum, 2013.

BAUMAN, Zygmunt. Modernidade Líquida. Tradução Plínio Dentzien. Rio de Janeiro: Jorge Zahar, 2001. 
BECK, Ulrich. World at Risk. Translated by Ciaran Cronin. Cambridge: Polity, 2009.

BRASIL. Constituição da República Federativa do Brasil, de 05 de outubro de 1988. Diário Oficial da União. Brasília/DF, 1988. Disponível em:

<http://www.planalto.gov.br/ccivil_03/constituicao/constituicaocompilado.htm>. Acesso em 13 fev. 2017.

BRASIL. Câmara dos Deputados. Proposta de Emenda à Constituição $n^{\circ}$ 287/2016. Disponível em: <http://www.camara.gov.br/proposicoesWeb/fichadetramitacao?idProposicao=2119881 . Acesso em 13 dez. 2016.

BRASIL. Instituto Brasileiro de Geografia e Estatística. Síntese de Indicadores Sociais: uma análise das condições de vida da população brasileira: 2015. Rio de Janeiro: IBGE, 2015. Disponível em: <http://biblioteca.ibge.gov.br/visualizacao/livros/liv95011.pdf〉. Acesso em 12 dez. 2016.

BRASIL. Lei Ordinária Federal no 10.741/2003. Estatuto do Idoso. Diário Oficial da União. Brasília/DF, 2003. Disponível em:

<http://www.planalto.gov.br/ccivil_03/leis/2003/110.741.htm>. Acesso em 13 fev. 2017.

BRASIL. Ministério da Fazenda. Secretária da Previdência. Resultado do Regime Geral de Previdência Social (RGPS) - 2016. 2017. Disponível em: <http://www.previdencia.gov.br/wpcontent/uploads/2017/01/Resultado-do-RGPS-2016-12-urbano-rural_web-VF-1.pdf >. Acesso em 10 fev. 2017

BRASIL. Secretaria do Tesouro Nacional (STN). Gasto Social do Governo Central de 2002 a 2015. 2016. (Disponível em:

<http://www.tesouro.fazenda.gov.br/documents/10180/318974/Gasto+Social+Governo+Central/c 4c3d5b6-8791-46fb-b5e9-57a016db24ec>. Acesso em 15 dez. 2016).

BRASIL. Supremo Tribunal Federal. Ação Direta de Inconstitucionalidade no 1.232/DF. Órgão Julgador: Plenário. Ministro Relator: Ilmar Galvão. Ministro Relator para o Acórdão: Nelson Jobim. Brasília/DF, julg. em 27 ago. 1998. Diário da Justiça. Disponível em:

$<$ http://redir.stf.jus.br/paginadorpub/paginador.jsp?docTP=AC\&docID=385451>. Acesso em 08 dez. 2016.

BRASIL. Supremo Tribunal Federal. Reclamação nº 4.374/PE. Órgão Julgador: Plenário. Ministro: Gilmar Mendes. Brasília/DF, julg. em 18 abr. 2013. Diário de Justiça Eletrônico. Disponível em:

<http://redir.stf.jus.br/paginadorpub/paginador.jsp?docTP=TP\&docID=4439489>. Acesso em 08 dez. 2016.

BRASIL. Supremo Tribunal Federal. Recurso Extraordinário $n^{\circ}$ 566.471/RN. Ministro Relator: Marco Aurélio. Brasília/DF. 2007. Disponível em:

<http://www.stf.jus.br/portal/processo/verProcessoAndamento.asp?numero=566471\&classe=RERG\&codigoClasse=0\&origem=JUR\&recurso=0\&tipoJulgamento=M > . Acesso em 13 fev. 2017.

BRASIL. Supremo Tribunal Federal. Recurso Extraordinário $n^{\circ}$ 657.718/MG. Ministro Relator: Marco Aurélio. Brasília/DF. 2007. Disponível em: 
<http://www.stf.jus.br/portal/processo/verProcessoAndamento.asp?numero=657718\&classe=RERG\&codigoClasse=0\&origem $=J U R \&$ recurso=0\&tipoJulgamento=M $>$. Acesso em 13 fev. 2017.

CORTINA, Adela. Ética sin moral. $7^{\mathrm{a}}$ ed. Madrid: Tecnos, 2007.

CORTINA, Adela. Razón comunicativa y responsabilidad solidaria. $2^{\mathrm{a}}$ ed. Salamanca: Sígueme, 1988.

CRIPPA, Davide. A solução cartesiana da quadratura do círculo. Scientiae Studia. Revista Latino-Americana de Filosofia e História da Ciência. São Paulo, vol. 08, nº 04, p. 597-621, 2010.

DINIZ, Maria Helena. Sistematização: problema central da Ciência Jurídica. Revista de Direito Brasileira. São Paulo, vol. 13, nº 6, p. 88-94, jan./abr. 2016.

FARIA, Adriana Ancona de; SILVA, Roberto Baptista Dias da. Direito à alimentação, transferência de renda e progressividade: o caso do programa bolsa família no Brasil. Revista Jurídica da Presidência. Brasília, vol. 18, n 114, p. 145-168, fev./maio 2016.

GIAMBIAGI, Fabio; TAFNER, Paulo. Demografia: a ameaça invisível: o dilema previdenciário que o Brasil se recusa a encarar. Rio de Janeiro: Elsevier, 2010.

KING, Jeff. Judging Social Rights. Cambridge: Cambridge University Press, 2012.

KLATT, Matthias. Positive Rights: Who decides? Judicial review in balance. International Journal of Constitutional Law. Oxford, vol. 13, nº 02, p. 354-382, 2015.

LINHARES, José Manuel Aroso. A "Abertura ao Futuro" como Dimensão do Problema do Direito. Um "correlato" da pretensão de autonomia? In: NUNES, António José Avelãs; COUTINHO, Jacinto Nelson de Miranda (coord.). O direito e o futuro - o futuro do direito. Coimbra: Almedina, 2008, p. 391-429.

LIPOVETSKY, Gilles. Os Tempos hipermodernos. Tradução Mário Vilela. São Paulo: Editora Barcarolla, 2004.

LOUGHLIN, Martin. Foundations of Public Law. New York: Oxford University Press, 2010.

MCCRUDDEN, Christopher. Human Dignity and Judicial Interpretation of Human Rights. European Journal of International Law. Oxford, vol. 19, n 4, p. 655-724, 2008.

MONIZ, Ana Raquel Gonçalves. Socialidade, Solidariedade e Sustentabilidade. In: LOUREIRO, João Carlos; SILVA, Suzana Tavares da (coord.). A Economia Social e Civil - Estudos. Coimbra: Instituto Jurídico da Faculdade de Direito da Universidade de Coimbra, 2015, 61-104.

NOVAIS, Jorge Reis. Direitos sociais enquanto direitos fundamentais. Coimbra: Editora Coimbra, 2010.

O’CONNOR, John Joseph; ROBERTSON, Edmund F. Carl Louis Ferdinand Von Lindermann. In :_____ MacTutor History of Mathematics archive. March 2001. Disponível em: <http://www-groups.dcs.st-and.ac.uk/history/Biographies/Lindemann.html>. Acesso em 06 dez. 2016. 
PORTUGAL. Tribunal Constitucional. Acórdão no 349/1991. Disponível em: <http://www.tribunalconstitucional.pt/tc/acordaos/19910349.html\#_edn1>. Acesso em 13 dez. 2016

PORTUGAL. Tribunal Constitucional. Acórdão $n^{\circ}$ 509/2002. Disponível em: <http://www.tribunalconstitucional.pt/tc/acordaos/20020509.html>. Acesso em 08 dez. 2016.

QUEIROZ, Cristina. O Tribunal Constitucional e os Direitos Sociais. Coimbra: Coimbra Editora, 2014.

RAO, Neomi. On the use and abuse of dignity in constitutional law. Columbia Journal of European Law. New York, Vol. 14, Issue 2, p. 201-255, 2008.

RAVALLION, Martin. The Economics of Poverty: history, measurement, and policy. New York: Oxford University Press, 2016.

SAMPAIO, José Adércio Leite. Expectativa de Direito, Direito Adquirido como Franquias e Bloqueios da Transformação Social. In: ROCHA, Cármen Lúcia Antunes (Coord.). Constituição e Segurança Jurídica: direito adquirido, ato jurídico perfeito e coisa julgada. Estudos em homenagem a José Paulo Sepúlveda Pertence. $2^{a}$ ed. Belo Horizonte: Fórum, 2009, p. 265-344.

SANDEL, Michael. O que o dinheiro não compra: os limites morais do mercado. Tradução Clóvis Marques. $4^{\mathrm{a}}$ ed. Rio de Janeiro: Civilização Brasileira, 2013.

SARLET, Ingo Wolfgang. A Eficácia do Direito Fundamental à Segurança Jurídica: Dignidade da Pessoa Humana, Direitos Fundamentais e Proibição do Retrocesso Social no Direito Constitucional Brasileiro. In: ROCHA, Cármen Lúcia Antunes (Coord.). Constituição e Segurança Jurídica: direito adquirido, ato jurídico perfeito e coisa julgada. Estudos em homenagem a José Paulo Sepúlveda Pertence. 2a ed. Belo Horizonte: Fórum, 2009, p. 85-129.

SARMENTO, Daniel. Dignidade Humana: conteúdo, trajetória e metodologias. $1^{\mathrm{a}}$ ed. $1^{\mathrm{a}}$ reimpressão. Belo Horizonte: Fórum, 2016.

SOARES, Rogério Ehrhardt. Direito público e sociedade técnica. Prefácio José Joaquim Gomes Canotilho. Coimbra: Edições Tenacitas, 2008.

TAFNER, Paulo; BOTELHO, Carolina; ERBISTI, Rafael. Debates sobre a Previdência: confusões e polêmicas iniciais. In:______________ (Org.). Reforma da Previdenciária: a visita da velha senhora. Brasília: Gestão Pública, 2015, p. 71-88.

THOMSON, Koy. A Universal Social Minimum as a Foundation for Citizenship. IDS Bulletin. Brighton, vol. 38, number 3, p. 56-60, may 2007.

TUSHNET, Mark. Weak Courts, Strong Rights: Judicial Review and Social Welfare Rights in Comparative Constitutional Law. Princeton: Princeton University Press, 2008.

VERMEULE, Adrian. Judging under Uncertainty: an institutional theory of legal interpretation. Cambridge: Harvard University Press, 2006. 
WALDRON, Jeremy. John Rawls and the social minimum. In: . Liberal Rights. Collected papers 1981-1991. Cambridge: Cambridge University Press, 1993, p. 250-270.

WIDERQUIST, Karl. How the Sufficiency Minimum Becomes a Social Maximum. Utilitas. Cambridge, vol. 22, nº 04, p. 474-480, December 2010. 